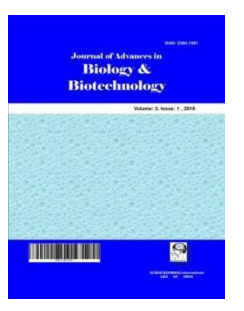

\title{
Total Phenols, Antioxidant Capacity and Antibacterial Activity of Manuka Honey Extract
}

\author{
Tsz Ching Chau ${ }^{1}$, Richard Owusu-Apenten ${ }^{1^{*}}$ and Poonam Singh Nigam ${ }^{1}$ \\ ${ }^{1}$ School of Biomedical Sciences, University of Ulster, Cromore Road, Coleraine, BT52 1SA, UK.
}

Authors' contributions

This work was carried out in collaboration between all authors. Authors ROA and PSN designed the study and wrote the protocol. Author TCC managed the analyses of the study, managed the literature searches, performed the statistical analysis, and wrote the first draft of the manuscript. All authors read and approved the final manuscript.

Article Information

DOI: $10.9734 / J A B B / 2017 / 37101$

Editor(s):

(1) Maria Teresa Cambria, Assistant Professor of Biochemistry, Department of Biomedical and Biotechnological Sciences, University of Catania, Division of Medical Biochemistry, Italy.

Reviewers:

(1) Fatma Yaylaci Karahalil, Maçka Vocational School, Karadeniz Technical University, Turkey. (2) Libonatti Carina, Universidad Nacional del Centro de la Provincia de Buenos Aires, Argentina. Complete Peer review History: http://www.sciencedomain.org/review-history/21616

\section{ABSTRACT}

Aims: To evaluate total phenols content (TPC), antioxidant capacity (TAC) and antibacterial activity of Manuka honey extract (MHE) and to compare such properties with those for unfractionated Manuka honey.

Study Design: In vitro study.

Place and Duration of Study: School of Biomedical Sciences, Ulster University, Coleraine, UK. Between September 2016 and September 2017.

Methodology: MHE was prepared by solvent extraction using ethyl acetate. TPC was determined by Folin-Ciocalteu assay. The iron (III) reducing antioxidant capacity (IRAC) method was used to determine TAC. Antibacterial activity was evaluated using disc diffusion assay and 96-well microtiter plate methods with absorbance measured at $600 \mathrm{~nm}$.

Results: The TPC for MHE was 30-fold higher than the value for Manuka honey (33420 $\pm 1685 \mathrm{mg}$ vs. $1018 \pm 78 \mathrm{mg} \mathrm{GAE} / \mathrm{kg})$ while TAC values were 100 -times greater $(83,198 \pm 7064 \mathrm{vs} .793 \pm 104$ TEAC, respectively). Antibacterial activity assessed by disc diffusion for Manuka honey $(18.5 \mathrm{~mm}$ on $S$. aureus and $20 \mathrm{~mm}$ on $E$. coll) was two times greater than for MHE $(9 \mathrm{~mm}$ for both $S$. aureus and E. coli). The 96-well microtiter plate assay confirmed the greater antibacterial activity for Manuka 
honey compared to equal concentrations MHE.

Conclusion: A polyphenol-rich Manuka honey extract with a high total antioxidant capacity, showed little or no antibacterial activity against $E$. coli and $S$. aureus in contrast with unfractionated Manuka honey.

Keywords: Manuka honey; manuka extract; total phenols; antioxidant; antibacterial.

\section{INTRODUCTION}

Infectious diseases continue to pose a threat to human health worldwide. Wound infections are commonly caused by bacterial pathogens [1-3]. Owing to the rising occurrence of antibioticresistant bacterial strains, alternative ancient remedies and plant-based products such as honey are being evaluated for therapeutic use. The medicinal importance of honey has been widely documented in the world's medical literature; standardized active Manuka honey has been registered as a wound care product with appropriate medical regulatory bodies [1-3]. Sherlock et al. [4] demonstrated antibacterial activity for Chilean Honey (Ulmo 90 honey) and New Zealand Manuka honey (UMF® 25+) against 5 MRSA strains. Ahmed and Othman [5] found that Tualang honey and Manuka honey could inhibit growth of Gram-positive MRSA strains including $S$. aureus and $S$ pyogenes and Gram-negative strains like $P$. aeruginosa, $E$. coli and Enterobacter cloacae [5].

Kwakman and Zaat [6] reported the antibacterial activity for Revamil ${ }^{\mathrm{TM}}$ honey and Manuka honey, the two leading medicinal grade honeys, arose from different mechanisms involving hydrogen peroxide, bee definsin, methylglyoxal, and unidentified components. Several studies proposed that phenolic compounds may contribute to the non-peroxide antibacterial activity of Manuka honey $[1,6]$. However, the specific contribution of phenolic components to the antibacterial action of Manuka honey has not been well investigated. The general aims of this project were to evaluate, the total phenols content (TPC), total antioxidant capacity (TAC), and antibacterial activity of an ethyl acetate extract from Manuka honey (Manuka Honey Extract; MHE) and to compare these characteristics with unfractionated Manuka honey.

\section{MATERIALS AND METHODS}

\subsection{Materials}

Manuka honey rated Unique Manuka Factor (UMF) $10+, 15+$ and 18+ were purchased from
Comvita Ltd (UK). Ethyl acetate, Folin-Ciocalteu reagent, sodium carbonate, gallic acid, Trizma base, ferrozine (3-(2-Pyridyl)-5,6-diphenyl-1,2,4triazine-4',4"-disulfonic acid sodium salt), ammonium iron (III) sulfate dodecahydrate, methanol and other chemicals were purchased from Sigma-Aldrich Ltd (Gillingham, UK). Nutrient broth (Oxoid), nutrient agar (Oxoid), and penicillin-streptomycin mixture (Pen-strep) were purchased from ThermoFisher Scientific (UK).Bacteria strains (Staphylococcus aureus, Escherichia coli) were obtained from School of Biomedical Sciences, Ulster University (UK).

\subsection{Preparation of Manuka Honey Extract (MHE)}

Honey extract was prepared using ethyl acetate as solvent as described by Tan et al. [7] with modification. Manuka honey (UMF 10+, 20g) was dispersed in $80 \mathrm{ml}$ of distilled-deionized water and $100 \mathrm{ml}$ ethyl acetate. The mixture was stirred using a magnetic stirrer for 24 hours. The emulsion formed was transferred to glass centrifuge tubes and centrifuged at 2,000 RPM for 15 minutes. The non-aqueous ethyl acetate phase was air-dried and the residue formed was re-dissolved in methanol solvent, filtered through $0.2 \mu \mathrm{m}$, and then stored at $-18^{\circ} \mathrm{C}$ until used. The solids content of MHE extract was determined by drying $50 \mu \mathrm{l}$ of MHE and weighing the residue.

\subsection{Determination of Total Phenols Content (TPC)}

The TPC was determined using Folin-Ciocalteu method adapted for microplate analysis as described previously $[8,9]$.

\subsection{Determination of Antioxidant Capacity}

Antioxidant capacity was determined using the iron (III) reducing antioxidant capacity (IRAC) method described recently [8]. The IRAC reagent was prepared by dissolving $20 \mathrm{mg}$ ferrozine dye in $9 \mathrm{ml}$ of Tris- $\mathrm{HCl}$ buffer $(\mathrm{pH} 7)$ and adding ferric (III) ammonium sulphate ( $4 \mathrm{mg}$ in $1 \mathrm{ml}$ water). For TAC determinations, samples of honey (20ul) 
were mixed with $280 \mu \mathrm{l}$ of ferrozine solution and incubated for $30 \mathrm{~min}$ at $37^{\circ} \mathrm{C}$. TAC assays were calibrated using trolox $(0-1000 \mu \mathrm{M})$ as antioxidant standard. A microplate reader (VersaMax, Molecular Devices, Sunnyvale, California, USA) was used for absorbance measurements at $562 \mathrm{~nm}$.

\subsection{Antibacterial Activity Screening}

\subsubsection{Antibacterial screening by disc diffusion assay}

The disc diffusion assay for antibacterial activity was carried out as described previously with minor modification [10] using two bacteria strains, one Gram-positive bacteria- $S$. aureus and one Gram-negative bacteria- E. coli. Working in laminar flow hood, bacterial inoculated broth $(200 \mu \mathrm{l})$ was transferred to blank nutrient agar plates (each bacteria $\mathrm{x} 2$ ), and allowed to dry. Thereafter, 6 blank paper discs were transferred onto agar plates using tweezer and ensuring equal spacing between each. Samples $(20 \mu \mathrm{ll})$ of Manuka honey (UMF10+ Manuka honey extract (MHE), 25\% UMF10+, 15+, 18+ Manuka honey) and controls (Pen-strep,) were slowly added to the blank disc and were left to dry briefly. Plates were incubated upside down overnight at $37^{\circ} \mathrm{C}$. The diameter of zones of inhibitions was measured after 24 hours in $\mathrm{mm}$.

\subsubsection{Micro-plate assay for antibacterial activity}

Samples of a 24-h grown liquid culture $(50 \mu \mathrm{L})$ were transferred to 96-well microtiter plate (x3), and $50 \mu \mathrm{L}$ of sterile honey sample $(25 \% \mathrm{w} / \mathrm{v}$ in water), MHE or antibiotic (Pen-strep) was added. The 96-well microtiter plates were incubated at $37^{\circ} \mathrm{C}$ for $24 \mathrm{~h}$ with gentle shaking and absorbances were read at $600 \mathrm{~nm}$. The antibacterial effect (\%) was determined from the expression, $100 *\left(1-\left(A_{H} / A_{0}\right)\right)$ where $A_{H}$ and $A_{0}$ are absorbance readings with and without honey treatment.

\subsection{Data Analysis}

Data analysis was performed using Microsoft excel and IBM SPSS Statistics Version 24. Correlation was obtained by Pearson correlation and significance was assessed in two-tailed at level of $P=0.01$.

\section{RESULTS AND DISCUSSION}

\subsection{Total Phenols Content and Antioxidant Capacity of Manuka Honey Extract}

TPC for MHE and unfractionated honey were expressed in mg-Gallic acid equivalent (GAE) per $\mathrm{kg}$ and are shown in Table 1. The TPC for Manuka honey UMF10+ was 1018.32 $\pm 78.84 \mathrm{mg}$ GAE/kg honey (Table 1) compared with values in the range of 430 - $2706 \mathrm{mg} \mathrm{GAE} / \mathrm{kg}$ reported previously [11]. The TPC for honey is known to vary with various factors, including monoflorality of honey, age and geographic origins of honey samples [12]. Compared to the original honey the, MHE had a 32.8-fold increase TPC. The TAC for honey evaluated in terms of IRAC is shown in Table 1 for ethyl acetate honey extract, and original honey (Table 1). The TAC for MHE was 105-fold increased compared to unfractionated Manuka honey. We reported that the TPC for Manuka honey was strongly correlated with antioxidant capacity and UMF rating (UMF5+,10+, 15+ and UMF18+) [9] but there was no specific reason for working with UMF $10+$ on this occasion.

Moniruzzaman et al. [12], Alvarez-Suarez et al [13] and others $[14,15]$ reported that phenols play an important role in the antioxidant capacity of honey. The dominating phenolic components identified in Manuka honey were phenyllactic acid and a group of methoxylated benzoic acids $[7,9]$. Other components in Manuka honey that contribute to the antioxidant capacity include flavonoids such as chrysin, quercetin, isorhamnetin and luteolin, phenolic acid like gallic acid, caffeic acid and syringinic acid [13].

\subsection{Antibacterial Activity}

Table 2 shows the antibacterial activity using the disc diffusion assay for $S$. aureus and $E$. coli. The MHE was adjusted to deliver similar quantities GAE per paper disc as was used for Manuka honey. For example, paper discs were loaded with 20- $\mu$ l Manuka honey UMF10+ (250 $\mathrm{g} / \mathrm{l}$ ) and hence the GAE loading per disc was $\left(250 \mathrm{~g} / \mathrm{l} * 20 \times 10^{-6} \mathrm{I} * 1.108 \times 10^{-3}(\mathrm{~g} \mathrm{GAE} / \mathrm{g})=\right.$ $5.1 \times 10^{-6}$ gGAE. After pre-diluting $\mathrm{MHE}$ by $33-$ fold, the GAE loading per disc was $(7.5 \mathrm{~g} / 1 \times 2 \times 10$ ${ }^{6} \mid \times 33.420 \times 10^{-3} \mathrm{~g}$ GAE $\left./ \mathrm{g}\right)=5.0 \times 10^{-6} \mathrm{gGAE}$. The results show clearly that the honey had antibacterial activity while MHE showed little or no antibacterial activity (Table 2). 
Table 1. Total phenols content and total antioxidant capacity of Manuka honey (UMF10+) and the manuka honey extract

\begin{tabular}{lll}
\hline Sample & TPC $(\mathbf{m g ~ G A E} / \mathbf{k g})$ & TAC $(\mathbf{m g}$ TE/kg) \\
\hline Honey (UMF10+) & $1018 \pm 79$ & $793 \pm 104.4$ \\
MHE & $33420 \pm 1685$ & $83198 \pm 7064$ \\
\hline${ }^{*}$ The total phenols content (TPC) and total antioxidant capacity (TAC) for Manuka honey (UMF10+) and ethyl \\
acetate extract from Manuka honey (MHE) as mg Gallic acid Equivalent (GAE)/ kg or mg Trolox Equivalent \\
\multicolumn{2}{c}{ (TE)/ kg sample }
\end{tabular}

Table 2. Measurement of zone of inhibition $(\mathrm{mm})$ by disc diffusion assay

\begin{tabular}{|c|c|c|c|c|c|c|}
\hline \multirow[t]{3}{*}{ Bacteria } & \multicolumn{6}{|c|}{ Zone of inhibition (mm) } \\
\hline & \multicolumn{2}{|c|}{ Controls } & \multicolumn{4}{|c|}{ Honey samples } \\
\hline & Pen-Strep & Methanol & UMF10+ & UMF15+ & UMF18+ & MHE \\
\hline S. aureus & 27.0 & 9.0 & 18.5 & 18.5 & 20.5 & 9.0 \\
\hline E. coli & 26.0 & 9.5 & 20.0 & 21.0 & 22.5 & 9.0 \\
\hline
\end{tabular}

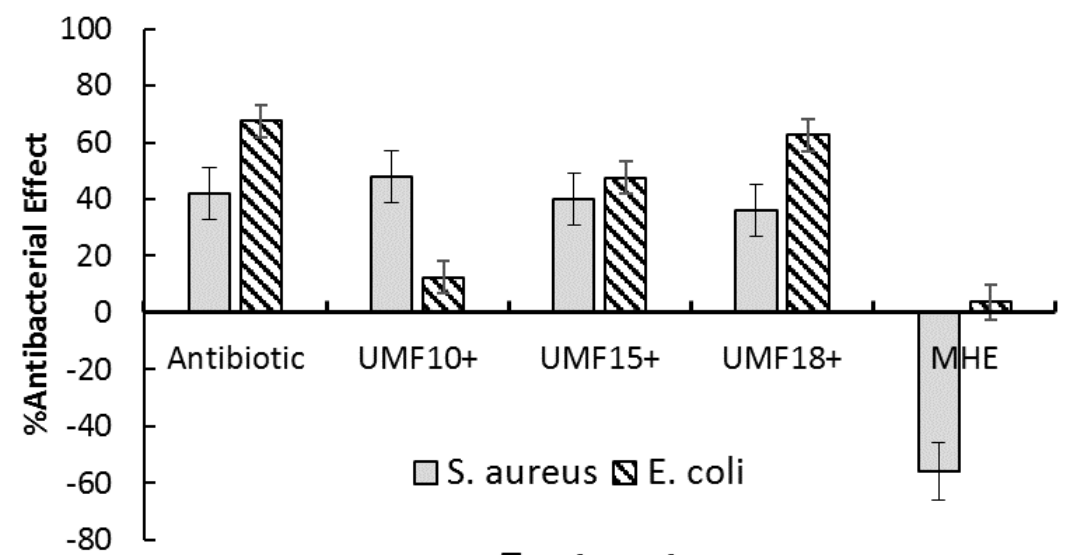

Treatments

Fig. 1. Antibacterial effect for manuka honey and manuka hone extract (MHE)

Tested with 96-well microtiter plats with E. coli or S. aureus. Penicillin-streptomycin was used as +ve control. Honey samples were 12.5\% (rated UMF 10+- UMF18+). MHE is Manuka Honey Extract See text for details

Antibacterial activity testing using microplate/ spectrophotometric method also showed that the honey extract had no antibacterial activity when tested at concentrations similar to those in honey (Fig. 1). For these tests, the exposure concentrations for $10+$ Manuka honey and MHE were $0.76 \mathrm{mM}$ and $0.74 \mathrm{mM} \mathrm{GAE}$, respectively. The microorganism used for testing ( $S$. aureus and $E$. coli) are known to be sensitive to Manuka honey $[5,16]$. Therefore, it was expected that screening (by disc diffusion assay and spectroscopic analysis) showed antibacterial activity with Manuka honey. Interestingly, MHE showed little or no antibacterial activity when tested at a similar concentration as honey.
Indeed, S. aureus measurements were consistent with increased growth after exposure to MHE (Fig. 1).

Based on current results, the polyphenols from Manuka honey may not be a major factor contributing to the antibacterial activity. The findings agree with previous reports, which noted that Manuka honey polyphenols (benzoic acids, cinnamic acids and flavonoids) could not account for entirely for the observed antibacterial activity $[17,18]$. Alternatively, the concentration of phenolic compounds from honey may be too low to contribute to antibacterial activity [6]. By contrast, there is considerable evidence showing 
a correlation between methylglyoxal content and antibacterial activity of Manuka honey [19] while only slight antibacterial activity was ascribed to the high sugar content and acidity [6]. The low antibacterial activity ascribed to MHE reported in the current paper, is different from the results obtained for extracts from 30 local honeys from Saudi Arabia, which showed that antibacterial activity was strongly correlated with total phenols content and antioxidant power [15] but there are differences in the approaches adopted for these studies. Manuka honey contains comparable levels of polyphenols and methylglyoxal [20], further research is underway to determine if such components interact and if this has possible consequences on antibacterial activity. The behavior of extracted phenols may also be different from antibacterial effects observed in the presence of other honey components. Further investigations are underway to consider the chemical constituents of Manuka honey that contribute to its antibacterial activity using the pathogenic strains used in this study.

\section{CONCLUSION}

Manuka honey organic extract, containing a high total phenols content and total antioxidant capacity showed little or no antibacterial activity. Further in-depth research is needed to understand the composition and characteristics of Manuka honey extracts.

\section{COMPETING INTERESTS}

Authors have declared that no competing interests exist.

\section{REFERENCES}

1. McLoone P, Warnock M, Fyfe L. Honey: A realistic antimicrobial for disorders of the skin. J Microbiol Immunol Infect. 2016; 49(2):161-7.

2. Carter DA, Blair SE, Cokcetin NN, Bouzo D, Brooks P. Therapeutic Manuka honey: No longer so alternative. Front Microbiol. 2016;7:569.

3. Oryan A, Alemzadeh E, Moshiri A. Biological properties and therapeutic activities of honey in wound healing: A narrative review and meta-analysis. J Tissue Viability. 2016;25(2):98-118.

4. Sherlock O, Dolan A, Athman R, Power A, Gethin G, Cowman S, Humphreys $H$. Comparison of the antimicrobial activity of Ulmo honey from Chile and Manuka honey against methicillin-resistant Staphylococcus aureus, Escherichia coli and Pseudomonas aeruginosa. BMC Compl Alt Med. 2010;10(1):47.

5. Ahmed $\mathrm{S}$, Othman $\mathrm{NH}$. Review of the medicinal effects of Tualang honey and a comparison with Manuka honey. MJMS. 2013;20(3):6-13.

6. Kwakman PHS, Zaat SA.J. Antibacterial components of honey. lubmb Life. 2012;64(1):48-55.

7. Tan ST, Holland PT, Wilkins AL, Molan PC. Extractives from New Zealand honeys. 1. White clover, Manuka and Kanuka unifloral honeys. J Agric Food Chem. 1988;36(3):453-460.

8. Owusu-Apenten R, Mohd Yusof HI, Nigam PS. Cryptic total antioxidant capacity of Manuka honey measured by a new microplate assay for iron (III) reducing antioxidant capacity (IRAC) and other methods. Food Chem; 2017. Submitted

9. Portokalakis I, Mohd Yusof HI, Ghanotakis D, Nigam P, Owusu-Apenten R. Manuka Honey-induced cytotoxicity against MCF7 breast cancer cells is correlated to total phenol content and antioxidant power. JABB. 2016;8(2):1-10.

10. Barlow R, Barnes D, Campbell A, Nigam PS, Owusu-Apenten R. Antioxidant, anticancer and antimicrobial, effects of Rubia cordifolia aqueous root extract. JABB. 2015;5(1):6-14.

11. Stephens JM, Schlothauer RC, Morris BD, Yang D, Fearnley L, Greenwood DR, Loomes KM. Phenolic compounds and methylglyoxal in some New Zealand Manuka and Kanuka honeys. Food Chem. 2010;120(1):78-86.

12. Moniruzzaman M, Sulaiman SA, Khalil MI, Gan SH. Evaluation of physicochemical and antioxidant properties of sourwood and other Malaysian honeys: A comparison with Manuka honey. Chem Cent J. 2013;7(1):138.

13. Alvarez-Suarez JM, Gasparrini M, ForbesHernández TY, Mazzoni L, Giampieri F. The composition and biological activity of honey: A focus on Manuka honey. Foods. 2014;3(3):420-432.

14. Can Z, Yildiz O, Sahin H, Turumtay EA, Silici S, Kolayli S. An investigation of Turkish honeys: Their physico-chemical properties, antioxidant capacities and phenolic profiles. Food Chemistry. 2015;180:133-41. 
15. Al-Hindi RR, Bin-Masalam MS, El-Shahawi MS. Antioxidant and antibacterial characteristics of phenolic extracts of locally produced honey in Saudi Arabia. Int J Food Sci Nutr. 2011;62(5):513-7.

16. Alzahrani HA, Alsabehi R, Boukraâ L, Abdellah F, Bellik Y, Bakhotmah BA. Antibacterial and antioxidant potency of floral honeys from different botanical and geographical origins. Molecules. 2012; 17(9):10540-9.

17. Weston RJ, Mitchell KR, Allen $\mathrm{KL}$. Antibacterial phenolic components of New Zealand Manuka honey. Food Chem. 1999;64(3):295-301.
18. Weston RJ, Brocklebank LK, Lu Y. Identification and quantitative levels of antibacterial components of some New Zealand honeys. Food Chem. 2000; 70(4):427-435.

19. Atrott J, Henle T. Methylglyoxal in Manuka honey-correlation with antibacterial properties. Czech J Food Sci. 2009; 27(Spec):S163-S165.

20. Kwok TH, Kirkpatrick G, Mohd Yusof HI, Portokalakis I, Nigam P, Owusu-Apenten R. Rapid colorimetric determination of methylglyoxal equivalents for Manuka honey. JABB. 2016;7(1):1-6.

(c) 2017 Chau et al.; This is an Open Access article distributed under the terms of the Creative Commons Attribution License (http://creativecommons.org/licenses/by/4.0), which permits unrestricted use, distribution, and reproduction in any medium, provided the original work is properly cited.

Peer-review history:

The peer review history for this paper can be accessed here: http://sciencedomain.org/review-history/21616 